\title{
STABILISASI TANAH EKSPANSIF DENGAN KOLOM KAPUR, DITINJAU TERHADAP POTENSI MENGEMBANG DAN NILAI INDEKS PLASTISITAS
}

\author{
Muhammad Adianto Sulistyo Hidayat ${ }^{1)}$, Bambang Setiawan ${ }^{2)}$, Noegroho Djarwanti ${ }^{2}$, \\ 1) Mahasiswa Fakultas Teknik, Prodi Teknik Sipil, Universitas Sebelas Maret \\ 2) Pengajar Fakultas Teknik, Prodi Teknik Sipil, Universitas Sebelas Maret \\ Jl. Ir. Sutami 36A, Surakarta 57126; Telp.0271-634524. Email: muhammadadianto13@gmail.com
}

\begin{abstract}
ABSTRAK
Tanah Ekspansif disebut tanah labil disebabkan perilakunya terhadap perubahan kadar air. Kadar air dalam kandungan tanah tersebut banyak, maka tanah akan mengalami pengembangan (swelling), sebaliknya jika kadar air dalam tanah tersebut sedikit, maka tanah tersebut akan mengalami susut. Kolom kapur berjumlah 7 buah ditanam pada drum uji yang berisi tanah ekspansif dan dibandingkan dengan drum yang hanya berisi tanah ekspansif. Pemberian air dilakukan selama 20 hari melalui pusat kolom sebanyak 1 liter tiap kolom perhari. Pengamatan dilakukan selama 20 hari hingga tanah jenuh. Pengamatan untuk penelitian ini dibagi menjadi 3 area, yaitu area 1, area 2, dan area 3. Pengujian Atterberg limit, Unconfined Compression Test (UCS), dan X-Ray Fluorescence (XRF) dilakukan setelah pengamatan selesai. Hasil penelitian ini adalah penambahan kolom kapur pada tanah ekspansif mampu mengurangi nilai perpindahan vertikal (swelling). Reduksi yang paling besar terjadi pada area 1 sebesar 7,13\% dan reduksi yang paling kecil terjadi pada area 3 sebesar 1,83\%. Nilai Indeks Plastisitas (PI) menurun dari 71,82\% menjadi 20,44\%. Nilai kohesi undrained (Cu) mengalami kenaikan dari 3,47 $\mathrm{kN} / \mathrm{m}^{2}$ menjadi $9,62 \mathrm{kN} / \mathrm{m}^{2}$.Kandungan $\mathrm{CaO}$ pada tanah ekspansif setelah penambahan kolom mengalami kenaikan dari $10,57 \%$ menjadi $23,25 \%$.
\end{abstract}

Kata Kunci : ekspansif, kolom kapur, pengaliran

\begin{abstract}
Expansive soil is called unstable soil due to its behavior to water content change. Water content in the soil content is many, so the soil will be swell, otherwise if the water content in the soil is little, then the soil will be shrink. This research uses the method of adding lime columns. 7 lime columns were planted on test drums containing expansive soil and compared with drums containing only expansive soil. Adding the water is carried out for 20 days through the center column as much as 1 liter in columns everyday. Observations were made for 20 days to saturated soil. Observations for this study were divided into 3 areas, there are area 1, area 2, and area 3. Atterberg limit test, Unconfined Compression Test (UCS), and X-Ray Fluorescence (XRF) were did after the observation was completed. The result of the research is the addition of lime column on expansive soil can reduce the value of vertical displacement (swelling). The greatest reduction occurred in area 1 the value is $7.13 \%$ and the smallest reduction occurred in area 3 the value is $1.83 \%$. The value of Plasticity Index (PI) decreased from $71.82 \%$ to $20.44 \%$. The value of cohesion undrained (Cu) increased from $3.47 \mathrm{kN} / \mathrm{m} 2$ to $9.62 \mathrm{kN} / \mathrm{m} 2$. CaO content in expansive soil after column addition increased from $10,57 \%$ to $23,25 \%$.
\end{abstract}

Keywords : expansive, lime column, drainage

\section{PENDAHULUAN}

Tanah Ekspansif disebut tanah labil dikarenakan perilakunya yang disebabkan oleh kadar air. Kadar air dalam kandungan tanah tersebut banyak, maka tanah akan mengalami pengembangan (swelling), sebaliknya jika kadar air dalam tanah tersebut sedikit, maka tanah tersebut akan mengalami susut. Peristiwa ini sangat berpengaruh pada jalan-jalan di sekitar tanah tersebut. Kebanyakan jalan di sekitar tanah tersebut mengalami kerusakan. Kapur merupakan material yang banyak ditemukan di Indonesia. Material ini mempunyai harga yang cukup terjangkau. Material kapur ada dua jenis yaitu kapur mati dan kapur aktif. Kapur mati adalah kapur yang sudah berbentuk bubuk / dihaluskan dan bila terkena air, kapur mati tidak bereaksi. Kapur aktif adalah kapur yang masih berbentuk bongkahan dan bila terkena air kapur aktif akan bereaksi. Penelitian ini akan menggunakan kapur aktif. Penelitian ini perlu dilakukan untuk mengurangi potensi mengembang dari tanah lempung ekspansif, dengan menggunakan kapur aktif sebagai bahan stabilisasi dari tanah ekspansif. Kolom kapur diletakkan pada drum yang berisi tanah ekspansif. Kolom yang diletakkan berjumlah tujuh kolom, yang nantinya akan dialiri melalui pusat kolom. Tujuan dialiri adalah agar kapur menyebar ke seluruh tanah dan dapat mengurangi pengembangan (swelling) pada tanah tersebut. 


\section{TINJAUAN PUSTAKA DAN LANDASAN TEORI Tanah Mengembang dan Kondisinya}

Pengembangan tanah umumnya terjadi pada tanah yang mengandung montmorillonite, (indeks plastisitas) PI yang tinggi, dan Zona aktif.

1. Tanah mengembang mengandung montmorillonite

Montmorillonite disebut juga mineral dua banding satu (2:1) karena satuan susunan kristalnya terbentuk dari susunan dua lempeng silika tetrahedral mengapit satu lempeng alumina oktahedral ditengahnya. Struktur kisinya tersusun atas satu lempeng $\mathrm{Al}_{2} \mathrm{O}_{3}$ di antara dua lempeng $\mathrm{SiO}_{2}$, karena struktur inilah montmorillonite dapat mengembang dan mengerut.

2. Tanah dengan plastisitas tinggi :

Tanah yang memiliki nilai (indeks plastisitas) PI yang tinggi cenderung mudah mengalami pengembangan. Tabel 1, menunjukkan hubungan potensi pengembangan lempung dengan Indeks Plastisitas (PI) yang disarankan oleh Chen (1988)

3. Zona Aktif:

Zona aktif adalah zona tanah di bagian atas yang dipengaruhi perubahan volume tanah akibat perubahan kadar air. Pengembangan tanah ekspansif terjadi akibat kenaikan kadar air di zona tersebut. Kadar air sangat berfluktuasi saat di alam, terutama di dekat permukaan tanah oleh faktor perubahan iklim akibat penguapan dan isapan akar tumbuhtumbuhan.

\section{Stabilisasi Tanah Dengan Kapur}

Potensi pengembangan tanah ekspansif menjadi berkurang bila tanah dicampur dengan kapur. Ada dua tujuan utama penggunaan kapur untuk stabilisasi tanah, yaitu :

1. kapur untuk memodifikasi sifat- sifat tanah, yaitu untuk mengurangi plastisitas, mengurangi atau menghilangkan sifat kembang susut, menambah mudah dikerjakan, menambah diameter butiran dan lain-lain.

2. kapur ditujukan untuk stabilisasi tanah secara permanen. Kriteria untuk hal ini didasarkan pada kapasitas dukung, keawetan dan sebagainya.

\section{METODE PENELITIAN}

Penelitian ini menggunakan metode penambahan kolom kapur. Kolom kapur berjumlah 7 buah ditanam pada drum uji yang berisi tanah ekspansif dan dibandingkan dengan drum yang hanya berisi tanah ekspansif. . Pemberian air dilakukan selama 20 hari melalui pusat kolom sebanyak 1 liter per kolom. Pengamatan dilakukan selama 20 hari hingga tanah jenuh. Pemilihan waktu 20 hari diasumsikan tanah pada model test akan jenuh pada hari ke 15, sehingga dipilih 20 hari untuk mengetahui keadaan yang benar- benar asimtut. Pengamatan untuk penelitian ini dibagi menjadi 3 area, yaitu area 1, area 2, dan area 3. Sketsa pengamatan dari penelitian ini ditujukkan pada Gambar 1 dibawah ini.

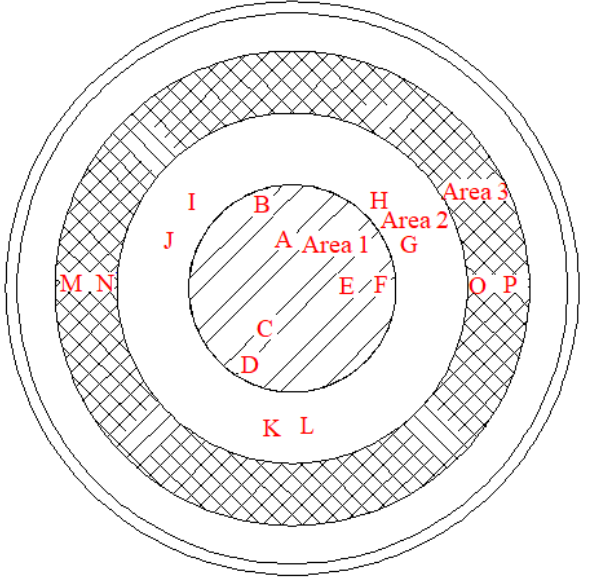

Model test kolom kapur

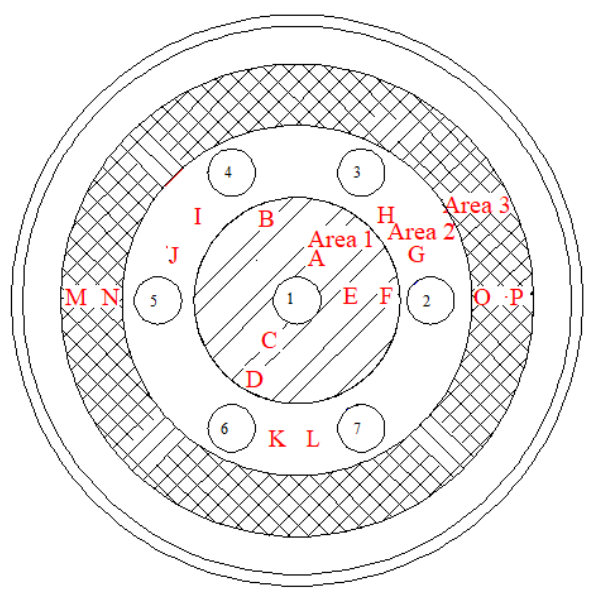

Model test pembanding

Gambar 1.Sketsa pengamatan pada model test kolom kapur dan pembanding

Pengujian Atterberg limit, Unconfined Compression Test (UCS), dan X-Ray Fluorescence (XRF) dilakukan setelah pengamatan selesai. Tujuan ketiga pengujian tersebut untuk mengetahui sifat dan karakteristik tanah setelah penambahan kolom kapur. 
HASIL DAN PEMBAHASAN

Perbandingan hasil Atterberg Limit sebelum dan sesudah penambahan kolom kapur

Hasil perbandingan Atterberg Limit dapat dilihat pada Tabel 1 dibawah ini.

Tabel 1. Perbandingan hasil Atterberg Limit

\begin{tabular}{c|c|c|c|c}
\hline Parameter & Satuan & Tanpa Kolom & Dengan Kolom & Ket \\
\hline Batas Cair & $\%$ & 114,05 & 92,29 & Turun \\
\hline Batas Plastis & $\%$ & 42,23 & 71,85 & Naik \\
\hline Indeks Plastis & $\%$ & 71,82 & 20,44 & Turun \\
\hline
\end{tabular}

Penambahan kolom kapur pada tanah ekspansif menaikkan nilai Plastic Limit (PL) dan menurunkan nilai Liquid Limit (LL), dan Plasticity Index (PI) seperti terlihat pada Tabel 1 diatas. Perubahan nilai ini mengakibatkan perubahan sifat pada tanah ekspansif, karena kapur mengikat butiran-butiran pada tanah ekpansif akibat dari reaksi kapur dengan air. Nilai Plasticity Index (PI) pada tanah dengan kolom kapur mengalami penurunan yang sangat besar yaitu dari $71,82 \%$ menjadi 20,44\%, berarti daerah plastis menjadi sangat sempit sehingga pengaruh kadar air menjadi kecil dan tanah tidak mudah mengembang.

Perbandingan hasil Unconfined Compression Test (UCS), sebelum dan sesudah penambahan kolom kapur

Hasil perbandingan Unconfined Compression Test (UCS) dapat dilihat pada Tabel 2 di bawah ini.

Tabel 2. Perbandingan hasil Unconfined Compression Test (UCS)

\begin{tabular}{c|c|c|c}
\hline Parameter & $\begin{array}{c}\text { Tanpa Kolom } \\
\text { Kapur }\end{array}$ & $\begin{array}{c}\text { Dengan Kolom Kapur pada } \\
\text { Area 3 }\end{array}$ & $\begin{array}{c}\text { Dengan Kolom Kapur pada } \\
\text { Area 1-2 }\end{array}$ \\
\hline $\begin{array}{c}\text { Kohesi undrained }(C u), \\
\left(\mathrm{kN} / \mathrm{m}^{2}\right)\end{array}$ & 3,47 & 4,37 & 9,62 \\
\hline $\begin{array}{c}\text { Kuat tekan bebas }(q u), \\
\left(\mathrm{kN} / \mathrm{m}^{2}\right)\end{array}$ & 6,94 & 8,74 & 19,24 \\
\hline
\end{tabular}

Nilai kohesi undrained $(\mathrm{Cu})$ tanpa kolom kapur $3,47 \mathrm{kN} / \mathrm{m}^{2}$ mengalami peningkatan menjadi 4,37 $\mathrm{kN} / \mathrm{m}^{2}$ dengan sampel uji yang diambil berada jauh dari kolom kapur. Peningkatan yang signifikan terjadi dengan sampel yang diambil dekat dengan kolom kapur, dari $3,47 \mathrm{kN} / \mathrm{m}^{2}$ menjadi $9,62 \mathrm{kN} / \mathrm{m}^{2}$. Kuat tekan bebas (qu) juga mengalami peningkatan. Nilai (qu) tanpa kolom kapur $6,94 \mathrm{kN} / \mathrm{m}^{2}$, setelah menggunakan kolom kapur menjadi 8,74 $\mathrm{kN} / \mathrm{m}^{2}$. Peningkatan yang signifikan terjadi dengan sampel yang diambil dekat dengan kolom kapur, dari $6,94 \mathrm{kN} / \mathrm{m}^{2}$ menjadi $19,24 \mathrm{kN} / \mathrm{m}^{2}$.

Perbandingan hasil pengujian utama

Perbandingan perpindahan vertikal tanah pada area 1, area 2 , dan area 3

Perbandingan dari 3 area ini dapat dilihat pada Gambar 4 dibawah ini.

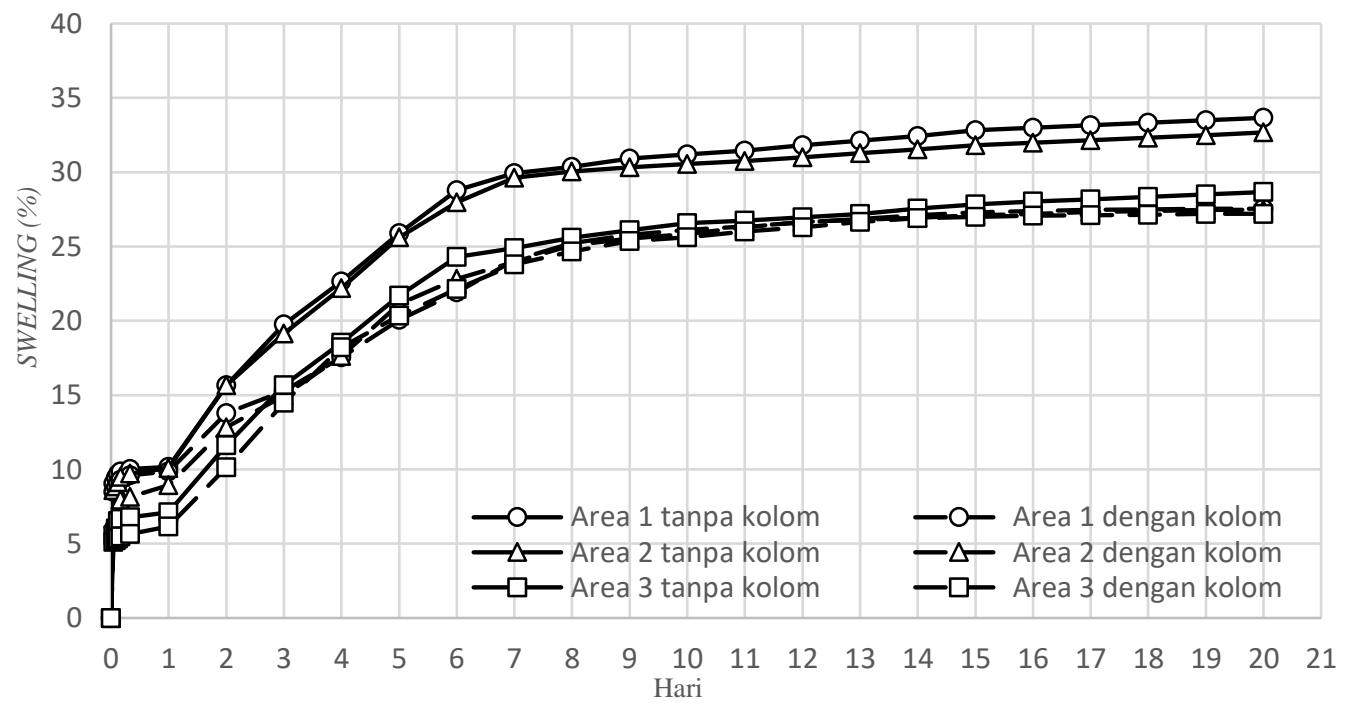


Gambar 2. Perbandingan perpindahan vertikal (swelling) area 1, area 2, dan area 3

Gambar 2 menunjukkan area 1 dan area 2 mengalami reduksi yang cukup signifikan, berbeda dengan area 3 yang mengalami reduksi tetapi tidak terlalu signifikan. Perbedaan reduksi yang terjadi pada area 1 dan area 2 diduga karena letak area tersebut yang berada diantara kolom kapur. Reaksi panas yang dihasilkan antara kapur dan air diduga mampu mengurangi perpindahan vertikal (swelling) pada area 1

dan area 2. Letak area 3 yang tidak diantara kolom dan jauh dari kolom diduga menjadi penyebab kecilnya reduksi yang terjadi pada area 3. Reaksi panas yang disebabkan oleh kapur dan air diduga tidak terlalu memberikan efek pada area 3.

Pembahasan lebih lanjut dilakukan pada titik D, titik J, dan titik P. Pemilihan ketiga titik ini karena pada area 1 dan area 2 perpindahan vertikal (swelling) yang paling besar terjadi pada titik D dan J. Titik P yang terletak pada area 3 tidak mengalami reduksi setelah penambahan kolom kapur.

\section{Perbandingan perpindahan vertikal tanah pada titik $\mathbf{D}$ (area 1)}

Titik D mengalami reduksi nilai perpindahan vertikal sebesar $8 \%$, pada model test pembanding dan model test yang menggunakan kolom kapur. Perbandingan perpindahan vertikal (swelling) pada titik D dapat dilihat pada Gambar 3.

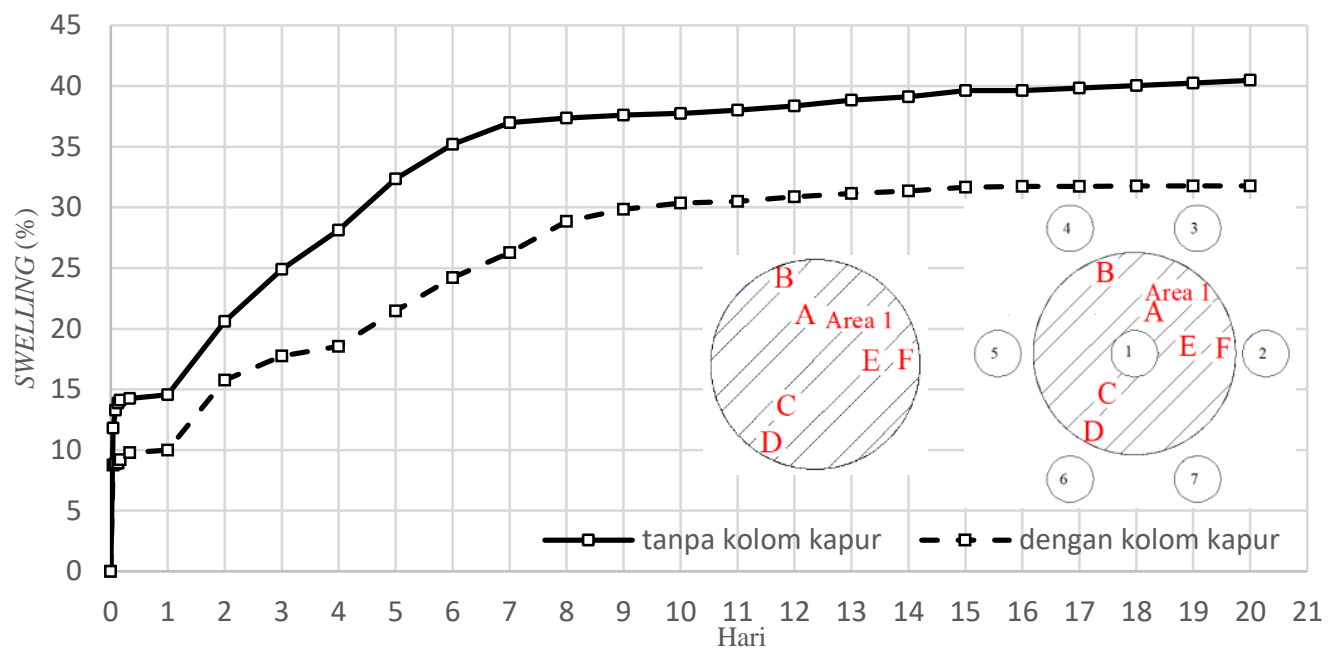

Gambar 3 Perpindahan vertikal pada titik D

Gambar 3 menunjukkan bahwa pada hari pertama pemberian air model test dengan kolom kapur memiliki nilai perpindahan vertikal (swelling) yang lebih rendah daripada model test pembanding, pada titik ini reduksi sudah terjadi pada hari pertama. Reduksi ini terjadi diduga karena reaksi kapur dengan air yang menghasilkan panas dan letak titik D pada area 1 yang berada diantara kolom. Hari ke 14 pada model test dengan kolom kapur menunjukkan keadaan yang mulai asimtut, sedangkan pada model test pembanding mulai mengalami keadaan asimtut pada hari ke 18 .

\section{Perbandingan perpindahan vertikal tanah pada titik $\mathrm{J}$ (area 2)}

Titik J mengalami nilai reduksi perpindahan vertikal sebesar $6 \%$, pada model test pembanding dan model test yang menggunakan kolom kapur. Perbandingan perpindahan vertikal (swelling) pada titik J dapat dilihat pada Gambar 4.

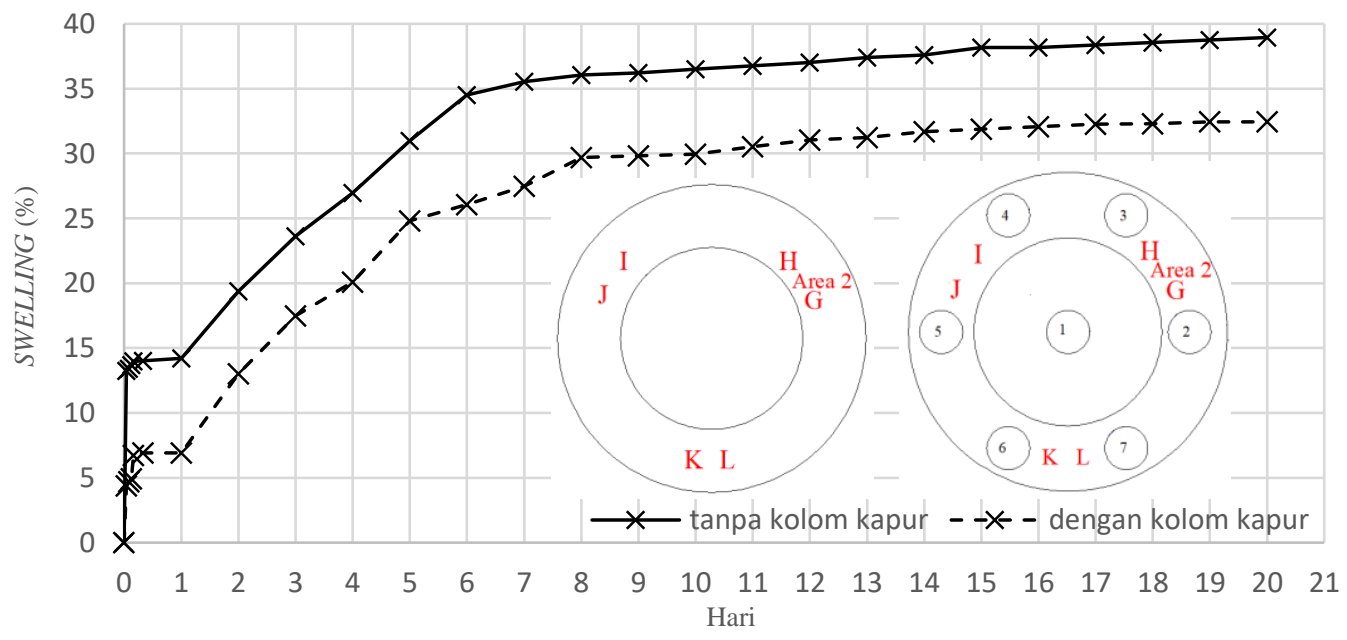


Gambar 4 Perpindahan vertikal pada titik J

Gambar 4 menunjukkan bahwa pada hari pertama pemberian air model test dengan kolom kapur memiliki nilai perpindahan vertikal (swelling) yang lebih rendah daripada model test pembanding, pada titik ini reduksi sudah terjadi pada hari pertama. Reduksi ini terjadi diduga karena reaksi kapur dengan air yang menghasilkan panas dan letak titik J pada area 2 yang berada diantara kolom. Hari ke 17 pada model test dengan kolom kapur menunjukkan keadaan yang mulai asimtut, sama dengan keadaan model test pembanding mulai mengalami keadaan asimtut pada hari ke 17.

\section{Perbandingan perpindahan vertikal tanah pada titik $\mathbf{P}$ (area 3)}

Titik P pada model test pembanding memiliki nilai perpindahan vertikal (swelling) sebesar 32\%, sedangkan pada titik P yang berada di model test dengan kolom kapur mempunyai nilai perpindahan vertikal (swelling) sebesar 34\%. Penambahan kolom kapur pada titik ini tidak memberikan perubahan, tidak terjadi reduksi pada pada titik ini. Perbandingan perpindahan vertikal (swelling) pada titik P dapat dilihat pada Gambar 5.

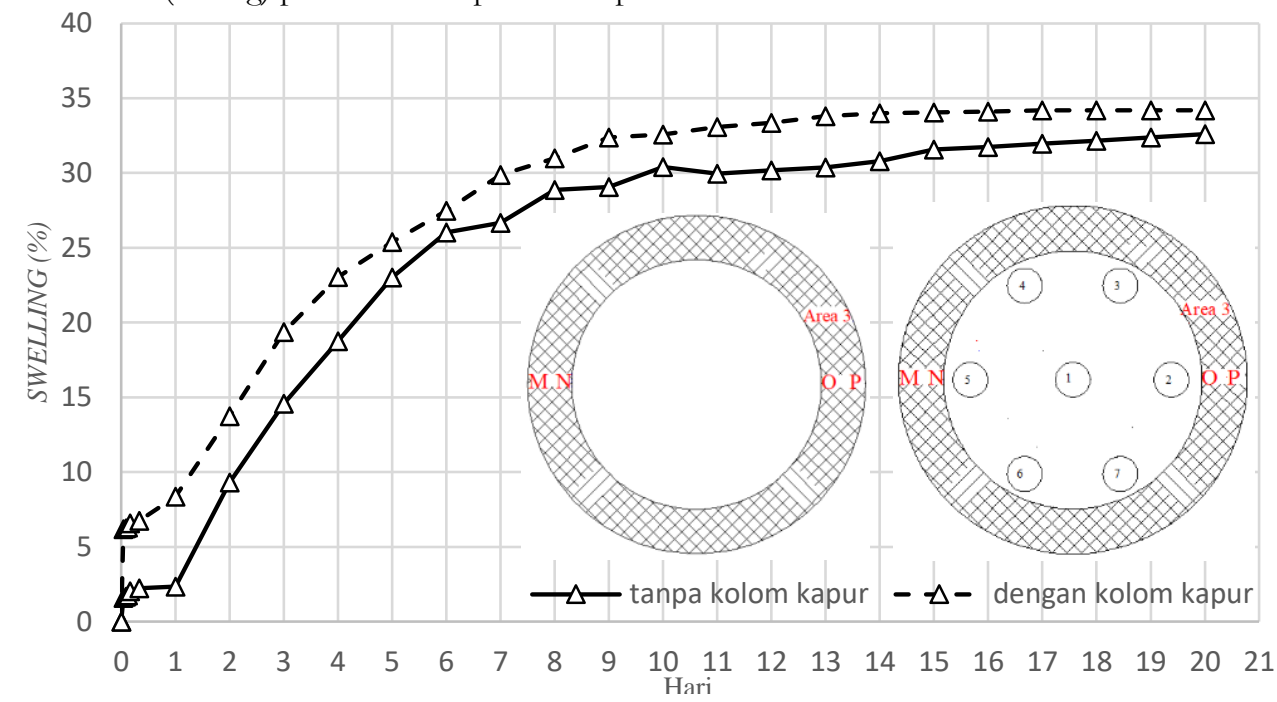

Gambar 5 Perpindahan vertikal pada titik P

Gambar 5 menunjukkan bahwa pada har1 pertama pembasahan model test dengan kolom kapur memiliki nilai perpindahan vertikal (swelling) yang lebih besar daripada model test pembanding. Hari pertama saat pemberian air sudah terjadi perbedaan yang signifikan. Nilai perpindahan vertikal (swelling) pada model test dengan menggunakan kolom kapur mempunyai nilai lebih tinggi dibandingkan dengan model test pembanding.

Reaksi panas yang dihasilkan dari kolom kapur dan air diduga tidak mengenai titik P. Jarak titik P yang jauh dari kolom diduga menjadi penyebabnya, karena sangat berbeda dengan area 1 dan area 2 . Letak area 1 dan area 2 yang berada dekat dengan kolom mengalami reduksi yang signifikan.

Semua titik yang berada pada area 1 dan area 2 mengalami reduksi, berbeda dengan area 3. Titik M, N, O pada area 3 mengalami reduksi, tetapi nilai reduksi dari ketiga titik tersebut tidak terlalu signifikan. Rata-rata reduksi setelah 20 hari yang paling besar ada pada area 1 sebesar 7,13\%, kemudian area 2 sebesar 6,08\% dan area 3 sebesar 1,83\%.

\section{Penyebaran Kapur}

Perubahan volume kapur tersebut diakibatkan karena reaksi kimia antara kapur dengan air yang menghasilkan panas. Proses pengamatan swelling yang dilakukan selama 20 hari menyebabkan kapur menjadi keras dan menggumpal. Perubahan bentuk volume kapur dapat dilihat pada Gambar 6.
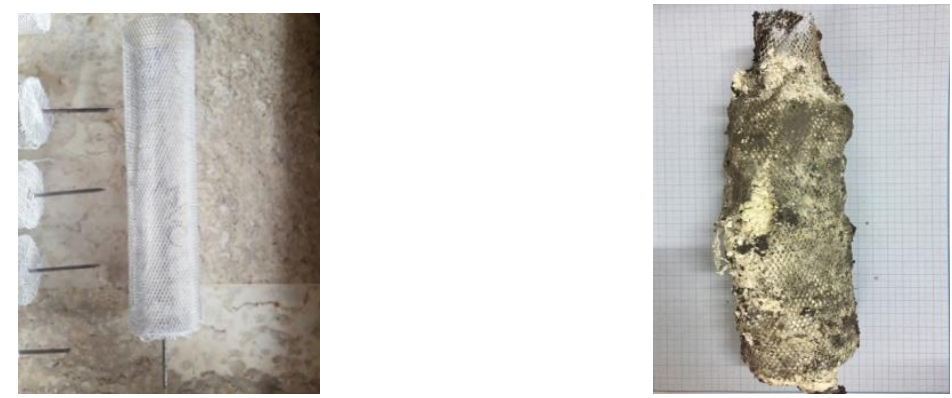

Gambar 6. Perubahan bentuk kolom kapur setelah 20 hari pembasahan 
Gambar 6 diatas sudah membuktikan bahwa adanya perubahan volume pada kolom kapur setelah pengamatan swelling. Perubahan volume kolom ini diakibatkan oleh reaksi kapur dengan air. Reaksi yang terjadi tidak hanya panas, tetapi kapur menjadi gumpalan yang keras setelah proses pengamatan swelling selama 20 hari.

Perubahan volume tersebut menujukkan indikasi bahwa kapur menyebar pada tanah, karena dengan perubahan tersebut kolom kapur mendesak tanah sehingga mampu mengurangi swelling. Pemberian air hari pertama pada kolom kapur menunjukkan reaksi panas yang mencapai $66^{\circ} \mathrm{C}$, dapat dilihat pada Gambar 7.

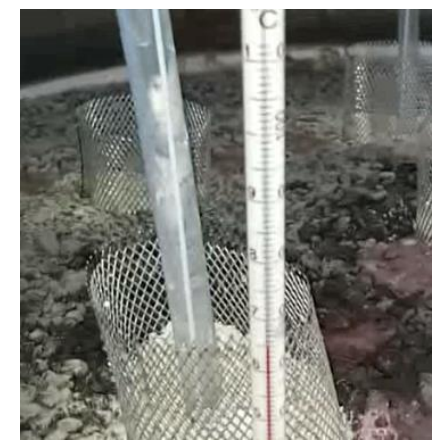

Gambar 7 Reaksi kolom kapur dengan air pada saat pembasahan

Pemberian air hari kedua temperatur mulai turun, reaksi kapur hanya terjadi pada saat hari pertama pembasahan, untuk lebih jelasnya dapat dilihat pada Tabel 4.

Tabel 4 Perubahan suhu pada kolom kapur

\begin{tabular}{c|c}
\hline Waktu (jam) & Temperatur $\left({ }^{\circ} \mathrm{C}\right)$ \\
\hline 0 & 66 \\
\hline 1 & 56 \\
\hline 2 & 47 \\
\hline 3 & 44 \\
\hline 4 & 43 \\
\hline 8 & 38 \\
\hline 24 & 31 \\
\hline 48 & 27 \\
\hline
\end{tabular}

Tabel 4 menunjukkan bahwa pada saat jam ke 0 yaitu pada saat pembasahan, temperatur mencapai suhu $66{ }^{\circ} \mathrm{C}$. Temperatur mulai turun pada setiap jam berikutnya hingga mencapai $27^{\circ} \mathrm{C}$ pada saat 48 jam atau hari kedua.

\section{KESIMPULAN}

Kesimpulan yang diperoleh dari hasil penelitian ini diantaranya adalah sebagai berikut :

a. Penambahan kolom kapur mampu menurunkan nilai Indeks Plastisitas (PI) dari 71,82\% menjadi 20,44\% .

b. Penambahan kolom kapur mampu menurunkan nilai Liquid Limit (LL) dari $114.05 \%$ menjadi $92.29 \%$.

c. Penambahan kolom kapur mampu menambah nilai kohesi undrained $(C u)$ dari $3,47 \mathrm{kN} / \mathrm{m}^{2}$ menjadi $9,62 \mathrm{kN} / \mathrm{m}^{2}$.

d. Penambahan kolom kapur mampu menambah nilai kuat tekan bebas (qu) dari $6,94 \mathrm{kN} / \mathrm{m}^{2}$ menjadi 19,24 $\mathrm{kN} / \mathrm{m}^{2}$.

e. Penambahan kolom kapur pada tanah ekspansif mampu mengurangi perpindahan vertikal (swelling) pada area 1 sebesar 7,13\%, area 2 sebesar $6,08 \%$, dan area 3 sebesar $1,83 \%$.

f. Kapur pada tanah ekspansif dalam model test dapat menyebar, dibuktikan dengan meningkatnya nilai senyawa penyusun kapur $\mathrm{CaO}$ pada uji $X R F$ dari $10,57 \%$ menjadi $23,25 \%$.

\section{DAFTAR PUSTAKA}

Irsyam, M., 1993, Tanah Mengembang Mekanisame dan Penanggulangan. Bandung : Institut Teknologi Bandung.

Hardiyatmo, H., C., 2014. Permasalahan dan Penanganan Tanah Ekspansif, Yogyakarta : Gajah Mada University Press. 
Hardiyatmo, H., C., 2014. Mekanika Tanah 1, Yogyakarta : Gajah Mada University Press. 